\title{
Comparative evaluation of NESTROFT and RDW as screening tests for beta thalassemia trait in pregnancy
}

\author{
Pritibala Patel, Nivedita Sarda, Renu Arora, Harsha Shailesh Gaikwad*
}

Department of Obstetrics \& Gynaecology, Vardhman Mahavir Medical College and Safdarjang Hospital, New Delhi, India

Received: 07 February 2015

Accepted: 01 March 2015

\section{*Correspondence:}

Dr. Harsha Shailesh Gaikwad,

E-mail: dongre.harsha1@gmail.com

Copyright: () the author(s), publisher and licensee Medip Academy. This is an open-access article distributed under the terms of the Creative Commons Attribution Non-Commercial License, which permits unrestricted non-commercial use, distribution, and reproduction in any medium, provided the original work is properly cited.

\begin{abstract}
Background: Thalassemia is the commonest inherited hemoglobinopathy. It is estimated that there are about 45 million carriers of the beta thalassemia gene and about 15000 affected infants are born every year in India, thereby contributing to about $10 \%$ of the total thalassemia babies born all over the world. Beta Thalassemia Trait (BTT) is asymptomatic while Beta Thalassemia Major (BTM) presents with severe anemia and requires lifelong blood transfusion, so emphasis must shift from treatment to screening and offering prenatal counseling to affected parents.

Methods: It was a hospital based cross sectional study on 500 antenatal women with microcytic hypochromic anemia with hemoglobin $<9 \mathrm{gm} \%$ and MCV $<80 \mathrm{fl}$ and all these women underwent Naked Eye Single Tube Red Cell Osmotic Fragility Test (NESTROFT), High Performance Liquid Chromatography (HPLC) and serum ferritin estimation.

Results: In our study the sensitivity and specificity of NESTROFT was $93.3 \%$ and $95.7 \%$ respectively compared to Red cell Distribution Width (RDW) with a sensitivity and specificity of $66.6 \%$ and $78.9 \%$ respectively.

Conclusions: For low resource settings like India, screening for beta thalassemia by NESTROFT is a cheaper and more reliable method with a high sensitivity and specificity and can be performed easily by paramedical staff.
\end{abstract}

Keywords: NESTROFT, Microcytosis, Thalassemia

\section{INTRODUCTION}

Thalassemia is the commonest inherited hemoglobinopathy. The incidence of beta thalassemia in different regions of India varies from $3 \%$ to $17 \%$ with a mean prevalence of $4 \% .^{1,2}$ It is estimated that there are about 45 million carriers of the beta thalassemia gene and about 15000 affected infants are born every year in India, thereby contributing to about $10 \%$ of the total thalassemia babies born all over the world. ${ }^{3}$ However, only $10 \%-15 \%$ of these children receive optimal treatment. ${ }^{4}$ Beta Thalassemia Trait (BTT) is asymptomatic and results in microcytosis and mild anemia while Beta Thalassemia Major (BTM) presents with severe anemia and requires lifelong blood transfusion. Thus, the birth of thalassemia child places considerable strain, not only on the affected child and its family, but also on the community and nation at large. With these limitations, emphasis must shift from treatment to prevention of such births in near future. The most feasible option is to test the mothers antenatally in early pregnancy preferably in the first trimester.

The hallmark of diagnosis for classical b-thalassemia carriers is a raised $\mathrm{HbA}_{2}$ varying between $3.5 \%$ and $4 \%$ depending on the method of estimation used. ${ }^{5}$ Today cation exchange - High Performance Liquid Chromatography (HPLC) has become the method of choice for quantification of $\mathrm{HbA}_{2}, \mathrm{HbF}$ (fetal) and other $\mathrm{Hb}$ subtypes. Although HPLC is the gold standard for 
diagnosis of BTT, is expensive and not universally available for population screening. Therefore, there is a need for a simple, low cost, rapid and reliable technique for the screening of the masses.

A number of different indicators, such as hemoglobin, hematocrit, serum ferritin, transferrin saturation, erythropoietin, erythrocyte protoporphyrin, serum iron, mean corpuscular volume, mean corpuscular hemoglobin concentration have been used to differentiate Iron Deficiency Anemia (IDA) from beta thalassemia. But the drawbacks of these tests are that many of them are expensive and require sophisticated laboratories, while others have been found to have a low specificity. Red cell Distribution Width (RDW) has been proposed to be a more sensitive indicator to establish the possible origin of microcytic hypochromic anemia. The RDW represents the coefficient of variation of the red blood cell volume distribution and can be considered an index of heterogeneity, the equivalent of anisocytosis observed in the peripheral blood smear. The morphology and function of erythrocytes at molecular level has been known to be disturbed due to iron deficiency anemia. Therefore, an increase in RDW values may occur in IDA allowing an early detection of IDA before reduction in Mean Corpuscular Volume (MCV) occurs. The thalassemia in contrast tends to produce a uniform microcytic red cell population without a concomitant increase in RDW. ${ }^{6}$ Naked Eye Single Tube Red Cell Osmotic Fragility Test (NESTROFT) detects the osmotic fragility of red cells. The principle of NESTROFT is based on the limit of hypo tonicity which the red cells can withstand. There is pronounced decrease in osmotic fragility of red cells in beta thalassemia. In the present study we compared two simple tests, the RDW and NESTROFT for screening of BTT and compared it with the gold standard HPLC in order to find a simple and reliable test for mass screening of antenatal patients.

\section{METHODS}

The present study was a hospital based cross sectional study carried out at the department of obstetrics and gynaecology, Vardhman Mahavir medical college and Safdarjung hospital, New Delhi, India, during September 2011 to March, 2013. In the study, all antenatal women Attending Antenatal Care (ANC) OPD were subjected to Complete Blood Count (CBC) including hemoglobin, Red Blood cell Count (RBC), Packed Cell Volume (PCV), Mean Corpuscular Volume (MCV), Mean Corpuscular Hemoglobin (MCH), Mean Corpuscular Hemoglobin Concentration (MCHC), RDW and peripheral smear. Women with other known haemoglobinopathies and hemoglobin <5 gm\% were excluded from the study. 500 women with microcytic hypochromic anemia with hemoglobin $<9 \mathrm{gm} \%$ and MCV $<80 \mathrm{fl}$ (femtolitre) were included in the study and all these women underwent NESTROF test, High Performance Liquid Chromatography (HPLC) and serum ferritin estimation. Efficacy of NESTROFT and RDW was evaluated for the detection of beta thalassemia using the HPLC as gold standard. None of the women had received blood transfusion. CBC including RDW was performed on fully automated machine SYSMEX KX-21, working on the principle of electrical resistance detection. Result of RDW was expressed as percentage and RDW $<18 \%$ was taken as positive test for diagnosing BTT. $\mathrm{HbA}_{2}$ (adult variant) and $\mathrm{HbF}$ estimation was done by using VARIANT II (Beta thalassemia short program) Bio-Rad Laboratories [K991127]. Two ml of sample collected in ethylenediamine tetraacetic acid (EDTA) vial was run on the system and level of $\mathrm{HbA}_{2}$ and $\mathrm{HbF}$ was obtained. $\mathrm{HbA}_{2} \geq 3.5 \%$ was taken as cut-off for diagnosis of beta thalassemia. Serum ferritin was measured by immunoassay system using $3 \mathrm{ml}$ of blood sample collected in special vials and transported to laboratory. A level less than $10 \mathrm{ng} / \mathrm{dl}$ was taken as indicative of iron deficiency anemia.

\section{NESTROF test}

As advocated by Mehta et al., ${ }^{6}$ NESTROFT was performed using $0.36 \%$ buffered saline solution. For this a stock solution of $10 \%$ buffered saline of PH 7.4 was prepared by dissolving sodium chloride $(\mathrm{NaCl}) 90 \mathrm{gm}$, disodium phosphate $\left(\mathrm{Na}_{2} \mathrm{HPO}_{4}\right) \quad 13.65 \mathrm{~g}$ and $\mathrm{NaHPO}_{4} .2 \mathrm{H}_{2} \mathrm{O} 2.4 \mathrm{~g}$ in one liter of distilled water.

Once made, the stock solution was kept well in Stoppard bottle in refrigerator for further use. From this $1 \%$ buffered saline was prepared from stock solution by $1: 10$ dilution with distilled water. For performing the NESTROF test $0.36 \%$ buffered saline solution was prepared by diluting $36 \mathrm{ml}$ of $1 \%$ buffered saline with 64 $\mathrm{ml}$ of distilled water to make $100 \mathrm{ml}$.

\section{Procedure of the test}

- Two ml of $0.36 \%$ buffered saline was taken in one tube $(10 \mathrm{~cm} \times 10 \mathrm{~cm})$ and $2 \mathrm{ml}$ distilled water was taken another tube.

- A drop of anticoagulated blood was added to both tubes and will be left undistributed for half an hour at room temperature.

- After half an hour both tubes were shaken and held against a white paper on which a thin black line was drawn.

- The line clearly visible through the contents of tube containing water acted as control.

Interpretation of NESTROF test: The test was considered negative when the line was similarly visible through the content of both tubes with buffered saline, and was considered positive when the line was not clearly visible through buffered saline solution. 


\section{Statistical analysis}

The data was analyzed by using SPSS statistic software. Pearson Chi- Square test was used to compare different parameters by converting them into categories. Data was analyzed by following tests: Student t-test to compare mean levels of the parameters between groups. Variations of $\mathrm{P}<0.05$ were considered significant. Sensitivity, specificity, positive and negative predictive value, diagnostic accuracy and Youden index of the test were calculated as validity statistics by the following formulae:

Sensitivity: $100 \times \mathrm{TP} \div(\mathrm{TP}+\mathrm{FN})$

Specificity: $100 \times \mathrm{TN} \div(\mathrm{TN}+\mathrm{FP})$

Positive predictive value: $100 \times \mathrm{TP} \div(\mathrm{TP}+\mathrm{FP})$

Negative predictive value: $100 \times \mathrm{TN} \div(\mathrm{TN}+\mathrm{FN})$

Accuracy: $(\mathrm{TP}+\mathrm{TN}) \div \mathrm{N}$

Youden index: Sensitivity + Specificity -1

Youden's index takes into account both sensitivity and specificity and gives an appropriate measure of validity of particular technique.

\section{RESULTS}

Out of five hundred-study populations, $30(6 \%)$ were positive and $470(94 \%)$ were negative for beta thalassemia using HPLC. Taking a cut-off of $18 \%$ for RDW, 119 (23.8\%) patients were positive and 381 $(76.2 \%)$ were negative for BTT. Using the NESTROFT, $48(9.6 \%)$ patients were positive and $452(90.4 \%)$ were negative for BTT (Table 1). Out of thirty patients who were BTT (true positive) by HPLC, $28(93.3 \%)$ were true positive by NESTROFT compared to only $20(66.6 \%)$ true positive by RDW. Similarly, out of 470 patients who were NBTT (true negative) by HPLC, 450 (95.7\%) were true negative by NESTROFT compared to 381 (78.9\%) true negative by RDW. Sensitivity, specificity, positive and negative predictive value of NESTROFT in the study were $93.3 \%, 95.7 \%, 58.3 \%$ and $99.57 \%$ respectively, while the same for RDW were $66.6 \%, 78.9 \%, 16.8 \%$ and $97.3 \%$ respectively (Table 2 ). $4.2 \%$ of patients were false positive and $6.6 \%$ were false negative by NESTROFT while $(21 \%)$ were false positive and $(33.3 \%)$ were false negative by RDW. Diagnostic accuracy and Youden index for NESTROFT and RDW were 95.6, 89\% and $78.2,45 \%$ respectively.

Mean hemoglobin was higher $(8.6 \pm 0.44 \mathrm{gm} / \mathrm{dl})$ in BTT than $8.1 \pm 0.69 \mathrm{gm} / \mathrm{dl}$ in NBTT $(\mathrm{P}<0.05)$. RBC count was higher $\left(4.84 \pm 0.268 \times 10^{12} / \mathrm{L}\right)$ in BTT than $(4.03 \pm$ $\left.0.408 \times 10^{12} / \mathrm{L}\right)$ in NBTT $(\mathrm{P}<0.05)$. Mean MCV was lower $(58.2 \pm 4.17 \mathrm{fl})$ in BTT than $(67.2 \pm 5.5 \mathrm{fl})$ in NBTT $(\mathrm{P}$ $<0.05)$. Mean RDW was lower in $(17.3 \pm 1.6) \%$ BTT than $(19.6 \pm 2.3) \%$ in NBTT $(\mathrm{P}<0.05)$. Mean $\mathrm{HbA}_{2}$ was higher $(4.1 \pm 0.64) \%$ in BTT than $(2.68 \pm 0.34) \%$ in NBTT (P <0.05) (Table 3). Mean serum ferritin level was higher $(11.3 \pm 1.8) \mathrm{ng} / \mathrm{dl}$ in BTT than NBTT $(9.5 \pm 1.6)$ ng/dl ( $\mathrm{P}<0.05)$. Partner counseling was offered to them and out of 30 positive cases, 2 cases had their husbands also affected with thalassemia trait. Both cases presented in advanced pregnancy i.e. after 20 weeks, so prenatal testing was not offered but they were counseled to report earlier in next pregnancy.

If testing is not offered to these women, they continue to receive oral iron thus increasing iron overload in body and if both partners are affected they have a chance to give birth to a baby with beta thalassemia major which requires lifelong blood transfusion and thus increasing the burden over family as well as society

Table 1: Comparison of results of NESTROFT and RDW with HPLC.

\begin{tabular}{|llll|}
\hline & HPLC & RDW & NESTROFT \\
\hline Positive & 30 & 119 & 48 \\
\hline Negative & 470 & 381 & 452 \\
\hline Total & 500 & 500 & 500 \\
\hline
\end{tabular}

Table 2: Comparison of efficacy of NESTROFT and RDW.

\begin{tabular}{|lll|}
\multicolumn{1}{|l}{} & $\begin{array}{l}\text { NESTROFT } \\
(\%)\end{array}$ & $\begin{array}{l}\text { RDW } \\
(\%)\end{array}$ \\
\hline Sensitivity & 93.3 & 66.6 \\
\hline Specificity & 95.7 & 78.9 \\
\hline Positive predictive value & 58.3 & 16.8 \\
\hline Negative predictive value & 99.57 & 97.3 \\
\hline \% of false positive & 4.2 & 21.06 \\
\hline \% of false negative & 6.6 & 33.3 \\
\hline Diagnostic accuracy & 95.6 & 78.2 \\
\hline Youden index & 89 & 45 \\
\hline
\end{tabular}

Table 3: Mean value of various RBC parameters.

\begin{tabular}{|c|c|c|}
\hline & Mean \pm SD & $P$ value \\
\hline \multicolumn{3}{|c|}{ HB (gm/dl) } \\
\hline NBTT & $8.1151 \pm 0.69199$ & \multirow{2}{*}{0.000} \\
\hline BTT & $8.6700 \pm 0.44424$ & \\
\hline \multicolumn{3}{|c|}{ RBC count $\left(\mathbf{x 1 0}^{6}\right)$} \\
\hline NBTT & $4.0397 \pm 0.40812$ & \multirow{2}{*}{0.000} \\
\hline BTT & $4.8467 \pm 0.26835$ & \\
\hline \multicolumn{3}{|c|}{ PCV $(\%)$} \\
\hline NBTT & $27.0224 \pm 2.04320$ & \multirow{2}{*}{0.003} \\
\hline BTT & $28.1533 \pm 1.1328$ & \\
\hline \multicolumn{3}{|c|}{ MCV (fl) } \\
\hline NBTT & $67.2352 \pm 5.5025$ & \multirow{2}{*}{0.000} \\
\hline BTT & $58.2707 \pm 4.1796$ & \\
\hline \multicolumn{3}{|c|}{ MCH (pg) } \\
\hline NBTT & $20.1559 \pm 1.6264$ & \multirow{2}{*}{0.000} \\
\hline BTT & $17.9162 \pm 0.91514$ & \\
\hline
\end{tabular}




\section{DISCUSSION}

The sensitivity of NESTROFT in the present study was $93.3 \%$, which is quite comparable with the sensitivity reported in other studies. ${ }^{7-10}$

All these studies have shown sensitivity above $90 \%$ varying from 91 to $100 \%$. The specificity in the present study was $95.7 \%$, which is comparable to results obtained by Chakrabarty ${ }^{8}$ and Bharat ${ }^{9}$. While sensitivity has been reported to be above $90 \%$ specificity has varied from $83.3 \%$ to $95 \%$. Although screening of the thalassemia trait using $0.36 \%$ buffered saline was successful in detecting $93.3 \%$ of subjects with this trait, it was false positive in $4.2 \%$ of non-beta thalassemia subjects. This can be explained by the fact that NESTROFT test is based on abnormal osmotic fragility of red cell that could occur in other conditions like sickle cell anemia, hemoglobin variants such as HbD, G-6PD deficiency and iron deficiency anemia. Therefore further confirmatory test like hemoglobin electrophoresis is to be done.

The positive predictive value of the test in present study was $58.3 \%$, which is comparable with study done by Chakrabarty. ${ }^{8}$

A lower positive productivity suggested false positive results probably due to associated iron deficiency, which requires confirmation by estimation of $\mathrm{HbA}_{2}$ levels. The positive predictive value of the test has significance in a particular population with high prevalence of the disease.

The negative predictive value of the test in carriers during the present study was $99.57 \%$, which is comparable with the results found by Bharat, ${ }^{9}$ Sumera $^{7}$ and Chakrabarty. ${ }^{8}$ In all these studies negative predictive value was more than $95 \%$. A high negative predictive value of the test is important as it almost rules out the possibility of beta thalassemia trait in the population tested negative with a particular screening test. Based on high negative predictive value, low cost and simplicity, we recommend the NESTROFT for mass screening of high-risk population in a low resource country like India (Table 4).

Table 4: Comparison of the sensitivity, specificity, positive and negative predictive values of the

NESTROFT using $0.36 \%$ buffered saline in the present study with those of other similar studies.

\begin{tabular}{|lllll|} 
& $\begin{array}{l}\text { Sensitivity } \\
(\%)\end{array}$ & $\begin{array}{l}\text { Specificity } \\
(\%)\end{array}$ & $\begin{array}{l}\text { PPV } \\
(\%)\end{array}$ & $\begin{array}{l}\text { NPV } \\
(\%)\end{array}$ \\
\hline Present study & 93.3 & 95.7 & 58.3 & 99.57 \\
\hline $\begin{array}{l}\text { Chakrabarty } \\
\text { et al. }{ }^{9}(2012)\end{array}$ & 94.12 & 95.2 & 41.02 & 99.7 \\
\hline $\begin{array}{l}\text { Afshan Sumera } \\
\text { (2012) }\end{array}$ & 93 & 88 & 74 & 97 \\
\hline $\begin{array}{l}\text { Vijay Bharat } \\
(2010)\end{array}$ & 100 & 98.5 & 96 & 100 \\
\hline $\begin{array}{l}\text { Singh \& Gupta } \\
(2008)\end{array}$ & 97.7 & 83.3 & 95.5 & 90.9 \\
\hline
\end{tabular}

The mean value of RDW in non-beta thalassemia group was significantly $(\mathrm{P}$ value $<0.000)$ higher $(19.66 \pm 2.33)$ than in beta thalassemia trait $(17.3 \pm 1.62)$. Keeping the cut off value of RDW as $18 \%$, the sensitivity, specificity, positive predictive value and negative predictive value of RDW in diagnosing beta thalassemia was found to be $66.0 \%, 78.9 \%, 16.8 \%$ and $97.3 \%$ respectively. On comparison with previous published studies, ${ }^{6,12}$ the present results favor the findings of Zeben et al., ${ }^{12}$ Thompson et al. ${ }^{11}$ and Flynn et al., 5 all of which showed a limited specificity of RDW. In the present study, if we keep the cut-off of $18.5 \%$, both sensitivity and specificity of RDW in diagnosing beta thalassemia is $70 \%$. If we further increase the cut-off value of RDW to $19 \%$, the sensitivity of RDW increases to $83.3 .0 \%$ but specificity drops to $61.9 \%$.

This result can be explained by the fact that anisocytosis found in iron deficiency anemia is due to the coexistence, in peripheral blood, of red cells produced in the bone marrow during progressive degrees of iron deficiency, giving rise to a mixed population of normocytic and increasingly microcytic cells. In beta thalassemia trait, there are no fluctuations in the underlying disorder and the bone marrow produces a uniform population of microcytic cells.

Serum Ferritin level was less than $10 \mathrm{ng} / \mathrm{dl}$ in 6 out of 30 cases of BTT which shows that iron deficiency may coexist with thalassemia. Although iron deficiency is less often seen in thalassemia due to enhanced enteric absorption of iron but it may coexist especially in country like India, where iron deficiency is so common.

On comparing NESTROFT and RDW, we found that sensitivity and specificity of the NESTROFT (93.3\% and $95.7 \%)$ was higher than RDW (66.6\% and 78.9\%).

Positive predictive value of NESTROFT, although low $(58.3 \%)$, was much higher than RDW (16.8\%). The negative predictive value of both NESTROFT and RDW was higher $(99.57 \%$ and $97.3 \%$ respectively) but here also NESTROFT exceeded RDW.

\section{CONCLUSION}

For low resource setting like India, screening by NESTROFT is a cheaper \& more reliable method (with a high sensitivity of $93.3 \%$, specificity $95.7 \%$ respectively) can be performed easily by paramedical staff.

Although NESTROF test is easy to perform, fast, cheap and does not require sophisticated equipment, there are certain limitations to this test. As observed during the study, it gives false positive results $(4.2 \%)$ in the case of patients with iron-deficiency anaemia. This would affect the specificity of the test in a population with a high incidence of iron-deficiency anaemia. RDW also gave false positive result in $21.06 \%$ patients. Therefore, subjects positive with either NESTROFT or RDW need to undergo further investigations to confirm diagnosis. 
Funding: No funding sources

Conflict of interest: None declared

Ethical approval: The study was approved by the institutional ethics committee

\section{REFERENCES}

1. Balgir RS. Control and prevention of the genetic load of haemoglobinopathies in India. Natl Med J India. 1999;12:234-8.

2. Indian Council of Medical Research. Collaborative study on thalassemia. In: ICMR, eds. ICMR Task Force Study. New Delhi: Indian Council of Medical Research; 1993.

3. Balgir RS. The burden of haemoglobinopathies in India and the challenges ahead. Curr Sci. 2000;79:1536-7.

4. Choudhry VP, Desai N, Pati HP. Current management of homozygous beta-thalassemia. Indian Pediatr. 1991;28:1221-9.

5. Flynn MM, Reppun TS, Bhagavan NV. Limitations of red blood cell distribution width (RDW) in evaluation of microcytosis. Am J Clin Pathol. 1986;85(4):445-9.

6. Mehta BC, Gandhi S, Mehta JB. Naked eye single tube red cell osmotic fragility test for betathalassemia: population survey. Indian J Haematol. 1988;6:187-90.

7. Afshan Sumera, Sulaiman Ahmed, S. M. Adnan Ali, Rafiq Khanani. Evaluation of NESTROFT as a marker of differentiation between $\beta$-thalassemia trait $\&$ iron deficiency anemia. Int $\mathbf{J}$ Collab Res Intern Med Public Health. 2012;4:1560-6.

8. Indranil Chakrabarti, Swapan Kumar Sinha, Nilanjana Ghosh, Bidyut Krishna Goswami. Betathalassemia carrier detection by NESTROFT: an answer in rural scenario? Iran J Pathol. 2012;7(1):1926.

9. Vijay Bharat, Subash Gupta, Rachna Gupta. Detection of carriers for $\beta$-thalassemia: a case study of Jammu (J\&K). Orient J Chem. 2010;26(1):199206.

10. Singh SP, Gupta SC. Effectiveness of red cell osmotic fragility test with varying degrees of saline concentration in detecting beta thalassemia trait. Singapore Med J. 2008;49(10):823-6.

11. Thompson WG, Meola T, Lipkin M Jr, Freedman ML. Red cell distribution width, mean corpuscular volume and transferrin saturation in diagnosis of IDA. Arch Intern Med. 1988;148:2128-30.

12. Van Zeben D, Bieger R, Van Wermeskerken RK, Castel A, Hermans J. Evaluation of microcytosis using serum ferritin and red blood cell distribution width. Eur J Haematol. 1990;54:106-9.

DOI: $10.5455 / 2320-1770 . i j r \operatorname{cog} 20150427$

Cite this article as: Patel P, Sarda N, Arora R, Gaikwad HS. Comparative evaluation of NESTROFT and RDW as screening tests for beta thalassemia trait in pregnancy. Int J Reprod Contracept Obstet Gynecol 2015;4:424-8. 